\title{
ARTE RUPESTRE Y ENTORNO ARQUEOLÓGICO: LAS CUENCAS DE LOS RÍOS TURÓN Y GUADALTEBA (MÁLAGA)
}

\author{
ROCK ART AND ARCHAEOLOGICAL ENVIRONMENT: THE BASINS \\ OF THE RIVERS TURÓN AND GUADALTEBA (MÁLAGA)
}

por

Rafael MaURa MiJares

RESUMEN Los trabajos de reconocimiento y localización de estaciones rupestres con arte esquemático en la provincia de Málaga que, con el apoyo del Departamento de Prehistoria e Historia Antigua de la U.N.E.D., vienen realizándose desde 1998, han puesto de manifiesto la necesidad de una serie de revisiones generales y particulares. La que aquí presentamos trata de relacionar, en un marco territorial definido, estas manifestaciones gráficas con el registro arqueológico, en un intento por vincularlas al proceso histórico.

\begin{abstract}
The labour of recognition and localization of places with schematic art in the province of Málaga that, with the support of the Department of Prehistory and Ancient History of the U.N.E.D., we are carrying out from 1998, have revealed the need of a chain of general and particular revisions. The one we present here, tries to relate that graphic expressions with the archaeological registry into a defined territorial framework, intending to link it with the historic process.
\end{abstract}

Palabras claves Arte rupestre esquemático. Contextualización arqueológica. Proceso histórico.

Key words Schematic rock art. Archaeological contextualization. Historic process.

\section{MARCO GEO-MORFOLÓGICO}

Junto con las depresiones de Ronda y Antequera, la zona Turón-Guadalteba, conforma el sector malagueño del Surco Intrabético. Aparecido a finales del Mioceno e instalado en sinclinales y fosas tectónicas, con predominio en este caso de los sedimentos pelágicos (margas y calizas) sobre los continentales (conglomerados y areniscas), el Surco Intrabético separa las Zonas Internas y Externas de las Cordilleras Béticas. Las Zonas 
Internas (más meridionales) están representadas en el entorno próximo por los Complejos Maláguide y Alpujárride y por la Dorsal Bética, con metamorfismo generalizado (metapelitas, rocas ultrabásicas y mármoles) del Paleozoico-Trías Medio/Superior. Las Externas (más septentrionales) se caracterizan por su tectónica de cobertera, con profusión de cabalgamientos, pliegues y fallas constituidas por carbonatos y margas, y gran desarrollo de Trías y Jurásico-Cretácico (Durán 1987: 49).

La zona se inscribe en un marco geográfico estratégicamente situado entre las depresiones de Añtequera y Ronda y la Hoya de Málaga, enlazándolas, tanto en sentido Este-Oeste como Norte-Sur, a través de los pasos naturales abiertos en las montañas circundantes, erigidas, a su vez, en accidentes de demarcación que la separan de aquellas. Cumplen este papel, por el Norte, las sierras de Peñarrubia, La Camorra y Cañete, por el Sur, las de Alcaparaín, Ronda y Carrasco, por el Este, las de Pizarra y Aguas, y por el Oeste, la Sierra de los Borbollos. Estos relieves montañosos delimitan un territorio caracterizado por un paisaje de valles y campiñas por los que discurren los ríos Turón y Guadalteba, cuyas cuencas, con una altitud media de unos 500 m.s.n.m., quedan separadas parcialmente por la Sierra de Ortejícar.

En la actualidad, la zona Turón-Guadalteba, comprende la práctica totalidad de los términos municipales de Ardales, Cañete la Real y Cuevas del Becerro, e incluye sectores más o menos amplios de los de Antequera, Campillos, Carratraca, Casarabonela, Teba, Almargen y Ronda. Cuenta con un interesante patrimonio histórico-artístico, muy notable en algunos casos, hecho que parece haber desviado la atención de los investigadores, ya que sus muestras de arte rupestre postpaleolítico son muy desconocidas y permanecían prácticamente inéditas. Sin Embargo, se trata de un conjunto paradigmático en el seno del contexto artístico local y regional en el que se incluye, ya que cuenta con todas las características principales que lo distinguen.

\section{ARTE RUPESTRE ESQUEMÁTICO}

Se registran en esta zona representaciones grabadas y pintadas en rojo y negro, pudiendo descubrirse desde el simple empleo de los dedos para aplicar la pintura hasta el uso de utensilios pictóricos. Así mismo, presenta aspectos formales de gran variedad, predominando las tipologías antropomorfas. Las estaciones se localizan tanto en abrigos rocosos como en cuevas, con o sin substrato paleolítico, y en soportes netamente funerarios.

He aquí una breve panorámica del arte esquemático en la zona, que será analizado de forma pormenorizada en otro lugar:

\section{1: Tajo del Cabrero (Ardales)}

Representación grabada a la intemperie de un antropomorfo el "phi".

\section{2: Necrópolis del Cerro de las Aguilillas (Campillos)}

En dos de sus tumbas en cueva artificial se localizaron motivos grabados consistentes en dos antropomorfos "tipo golondrina", uno de los cuales fue destruido durante el verano de 2000 (Espejo et al. 1994).

\section{3: Cueva de Ardales (Ardales)}

La presencia de una pequeña figura de arquero, rojo anaranjado y de factura esquemática, en esta gruta de fuerte acervo paleolítico ha generado cierta controversia sobre su reutilización como espacio artístico en épocas posteriores, como ocurre en las cuevas de la Pileta, La Victoria y Nerja. No obstante, y a pesar de la posible reinterpretación que sugieren otras figuras negras, esta posibilidad, así como la propia filiación esquemática del arquero, queda aún por demostrar. (Dams y Dams 1983: 120; Espejo y Cantalejo 1987a: 101). 


\section{4: Sima de la Curra (Carratraca)}

Conserva este cavernamiento numerosos vestigios pictóricos, entre los que destaca la figura en rojo de un antropomorfo en " $\mathrm{H}$ " invertida. El carácter funerario del yacimiento y la localización preferente de este motivo han sugerido que se tratara de algún tipo de ídolo (Sanchidrián 1984-1985).

\section{5: Raja de Retuntún (Casarabonela)}

Las manifestaciones artísticas de este abrigo se encuentran en un estado de conservación muy precario, debido, con cierta seguridad, al hundimiento de la bóveda primitiva que locubría y que dejó desprotegidos gran parte de los motivos. Sin embargo, aún se observan con dificultad veinte figuras en distintos tonos de rojo, algunas interesantes, como un antropomorfo oculado y varias representaciones humanas en "Y" o doble "Y" (Muñoz 1990; Maura 2003).

\section{6: Tajo del Molino, 1 (Teba)}

Situado en la cara Este del desfiladero del mismo nombre, es un angosto abrigo de iconografía monotemática, ya que se repite hasta siete veces el mismo motivo, probablemente representaciones de "estelas", en color rojo.

\section{7: Tajo del Molino, 2 (Teba)}

En la cara opuesta del mismo desfiladero y a mayor altura, se localiza este pequeño abrigo, cuyos restos pictóricos se reducen a tres grupos de trazos muy perdidos, uno de los cuales podría interpretarse como un antropomorfo en " $\mathrm{H}$ " invertida.

\section{8: La Cuevecilla (Teba)}

Abrigo de grandes proporciones con escaso número de figuras e iconografía similar a la de Raja de Retuntún.

\section{9: Casilla del Búho (Cañete la Real)}

Las pinturas registradas en este abrigo ocupan la pared del fondo de una hornacina que cierra la oquedad. En torno a trece figuras antropomorfas, pectiniformes, circulares e indeterminadas en negro, una treintena de trazos cortos de color rojo fueron dispuestos sin orden aparente. La agrupación de estas figuras en un lugar tan significativo del abrigo sugiere algún tipo de composición o escena (Maura 2001).

\section{0: Puerto del Viento (Ronda)}

Destaca este abrigo, localizado, paradójicamente, a gran altitud, por sus representaciones de barcos, algunas confusas pero otras bastante claras, todas en negro, acompañadas de otros signos muy concrecionados y de difícil apreciación (Dams y Dams 1984; Almagro-Gorbea 1987).

\section{CULTURA MATERIAL}

No se cuenta en la zona con dataciones directas o contextualizaciones en estadios culturales fechados de forma absoluta, ni se dan casos de superposiciones sucesivas que nos permitan distinguir períodos de realización. En estas circunstancias, toda tentativa de establecimiento de relaciones entre el arte esquemático y la cultura material nunca podrá llegar a ser objetiva y, desafortunadamente, el concepto vago de proximidad espacial "lógica" (Morales y Márquez 1984:176) se sigue presentando, aquí y ahora, como única alternativa. De entre todas sus variables, el análisis del registro arqueológico de las propias estaciones rupestres, cuando lo conservan, parece la más evidente, aunque esta relación de inmediatez no tenga por qué ser necesariamente vinculante. En este sentido, la valoración general de los abrigos como lugares en los que no suele detectarse otra actividad que la meramente artística viene condicionada, sobre todo, por la escasa o nula potencia 
estratigráfica de sus suelos (esto ocurre en todos los abrigos de la zona excepto en la Raja de Retuntún y en el Tajo de Molino, 1). Por el contrario, las cuevas y sepulcros sí se caracterizan por presentarse en contextos arqueológicos definidos. Conviene, pues, comenzar por repasar y actualizar los resultados de las actividades arqueológicas realizadas en ellos. No nos proponemos aquí glosarlos en toda su extensión, sino concretar los aspectos que entendemos de interés para esta investigación:

\section{— NECRÓPOLIS DE LAS AGUILILLAS:}

Las cuevas artificiales que componen esta necrópolis (Ramos et al. 1994; Espejo et al. 1994; Ramos et al. 1997) se distribuyen en el cerro que le da nombre en cuatro sectores, el primero de los cuales fue el que ofreció los grabados esquemáticos (estructuras 1 y 3 ). La tendencia tipológica de la arquitectura que registra este complejo funerario es relativamente homogénea desde un punto de vista estructural, tratándose de sepulturas de corredor y cámara de planta irregular a la que se agregan nichos secundarios. Al margen de este modelo se situaría la estructura $n^{\circ} 6$ (sector 3 ), construcción megalítica en cueva semiartificial de alargado pasillo, mediante el que se accede a dos cámaras alineadas, ambas con cubierta adintelada a base de grandes lajas de arenisca. A diferencia del resto de estructuras, localizadas en ladera, este sepulcro está situado sobre una cima desde la que se dominan tanto el embalse del Conde de Guadalhorce como el desfiladero de los Gaitanes.

Sólo las estructuras 4 y 5 (sector 2) ofrecieron documentación fiable respecto a la disposición de los enterramientos y ajuares (Ramos et al. 1994: 359-360). En contra de nuestros intereses, el sector 1 ha sido el más maltratado por el paso del tiempo y de los hombres, habiéndose registrado en asociación con estas estructuras una serie de materiales que demuestran una frecuentación y conocimiento del lugar en época tardorromana y medieval, así como su ocupación como refugio durante la Guerra Civil en la que, además, formó parte de la línea del frente. Resulta irónico que, después de superar tantos avatares, uno de los grabados de la tumba $n^{\circ} 3$ haya desaparecido recientemente víctima de una simple quema de leña. No obstante, este sector sí proporcionó interesantes materiales relacionados con los trabajos de construcción de las tumbas, como los picos, hachas talladas y cinceles hallados en el interior de las mismas y en sus alrededores (Espejo et al. 1999: 21). Otros restos de interés para esta investigación son las placas líticas bitriangulares relacionadas con la estructura $n^{\circ} 6$. Estas piezas presentan diferentes paralelismos formales en la provincia, tanto en el arte mueble -"venus" de Benaoján (Giménez Reyna 1941) o "ídolo" de Las Palomas (García, Martínezy Morgado 1995: 75-78)-, como en el rupestre, ya sean grabados -“ídolos" femeninos esquemáticos de la Cueva de Nerja (Sanchidrián 1982)- o pintados -tipo 1 del abrigo nº 16 de Peñas de Cabrera (Barroso y Medina 1989: 334)-.

Este modelo de enterramiento definido como complejo funerario de tumbas excavadas en la roca, permite una vinculación morfológica (Rivero 1986) con las también malagueñas necrópolis de Alcaide (Marqués y Ferrer 1979; 1983; Marqués 1987; Ferrer y Marqués 1986) y Peñas Prietas (García Serrano 1979-80), aunque para estas se hayan propuesto cronologías más antiguas, en torno al Calcolítico inicial para Peñas Prietas (García Serrano 1979-80: 375) y al Cobre pleno y final para Alcaide (Marqués y Ferrer 1983: 234)..A estas dos necrópolis deben sumarse las de Alameda y Humilladero, adscritas a un horizonte cultural paralelo al de Alcaide (Ferrer y Marqués 1986: 253). El encuadre cronológico al que se ha adscrito la necrópolis de Las Aguilillas, en los albores del II Mil. a.n.e., podría representar una perduración de los sistemas "colectivos" de inhumación y determinaría la "continuidad de organizaciones de base tribal, en el seno de procesos sociales cada vez más jerarquizados" (Ramos et al. 1999: 360). 


\section{- CUEVA DE ARDALES}

Varias son las publicaciones de carácter arqueológico relacionadas con este importante yacimiento (Giménez Reyna 1963; Cantalejo y Espejo 1988; 1995; Espejo y Cantalejo 1987 a y b; Cantalejo, Espejo y Ramos 1997; Ramos et al. 1987 b; 1995; 1997; 1997-98; Sanchidrián, Vivas y Fernández 1989). Además de los motivos artísticos paleolíticos y postpaleolíticos, se han registrado en ella conjuntos de cerámica lisas y decoradas fabricadas a mano, artefactos de sílex y restos humanos, testimonios que evidencian la ocupación neolítica de las Galerías Bajas con un espacio de hábitat en la Sala del Saco y otro para enterramientos en la de las Estrellas (Ramos et al. 1987 b: 145-157; 1997-98: 34; Cantalejo, Espejo y Ramos 1997: 89). Especial interés para nuestra investigación tiene el hallazgo de dos falanges, la primera de $5,7 \mathrm{~cm}$ de longitud, con decoración incisa -dos perforaciones a modo de ojos-y otros retoques (Ramos et al. 1987 b: 151) y la segunda, aún sin publicar, de $5,6 \mathrm{~cm}$ de largo que presenta perforación de lado a lado en uno de sus extremos, lo que hace suponer que debió tener un uso como colgante. En el Calcolítico, la selección de este tipo de soporte óseo para las representaciones de "ídolos" parece deberse a su relación formal con los bitriangulares (Bécares 1990: 90), entendidos como los elementos conceptualmente más básicos de representación corporal de dichos "ídolos" (Bécares 1990: 88). Muchas de estas falanges aparecen sin decorar o presentan escasas incisiones y/o perforaciones de diversa consideración. Las de Ardales, aunque asociadas a materiales neolíticos, podrían integrarse en este último grupo, con decoraciones simples, clasificado por $\mathbf{M}^{\mathrm{a}}$. J. Almagro como del tipo VI B. Sin embargo, las representaciones oculares no abundan en esta tipología, siendo más propias del tipo VI C, es decir, con rica decoración grabada o pintada. Las reminiscencias oculadas de la primera de las falanges de Ardales podrían relacionarse, pues, con las de este grupo, entre las que destacaremos las ya clásicas de Olelas, Los Millares, Almizaraque, Los Castellones y Bugalheira (Almagro 1973: 153-168. Fig. 26), a las que puede sumarse la de la Cueva de Belda (Leiva y Ruiz 1977; Ruiz y Leiva 1980-81), en la provincia de Málaga, si bien sus adscripciones cronológicas parecen remitirse a momentos posteriores.

También las Galerías Altas de esta cueva contienen motivos artísticos (Espejo y Cantalejo 1987 b: 121), sin que hayan sido, hasta ahora, estudiados en profundidad. Con cierta seguridad, se trata de formas expresivas paleolíticas, aunque puedan surgir dudas, muy poco razonables, para algunas de ellas. Durante el Calcolítico, estas galerías tuvieron un uso doméstico - por demostrar- y funerario (Sanchidrián, Muñoz y Fernández 1989: 211; Espejo y Cantalejo 1987 b: 123-124; Ramos et al. 1997-98: 35; Cantalejo, Espejo y Ramos 1997: 89), disponiendo de una entrada propia que permitía la iluminación con luz cenital de un buen tramo del sector principal (Espejo y Cantalejo 1987 b: 121), hasta su taponamiento en un momento posterior al III Mil.a.n.e. (Cantalejo, Espejo y Ramos 1997: 22; Ramos et al. 1997-98: 19-20). Es probable que las Galerías Altas fueran autónomas respecto a las Bajas, unidas espeleológicamente pero sin posibilidad de conexión humana en la Prehistoria (Espejo y Cantalejo 1987 b: 119-121). Sin embargo, la mayor dificultad de acceso es una colada de $12 \mathrm{~m}$ de altura, algo factible de superar en aquella época, sobre todo si tenemos en cuenta las evidencias prehistóricas de sistemas de progresión en cuevas presentes en la vecina Sima de la Curra (Sanchidrián 1984: 240), si bien es verdad que en el caso de Ardales no se ha hallado resto alguno de cordelería. Por otro lado, existen evidencias de que el corredor que comunica la Sala de la Olla con la del Redil fue taponado artificialmente, quedando así físicamente separados ambos espacios. La aceptación de que esta conexión no fue utilizada entonces supondría la posibilidad de establecer una cronología ante quem para el arquero de las Galerías Bajas, dado que las evidencias geológicas parecen apuntar a que la boca de acceso a estas quedó cerrada por causas naturales hacia finales del IV Mil. a.n.e. (Cantalejo, Espejo y Ramos 1997: 22).

No se ha detectado la presencia de materiales calcolíticos en las Galerías Bajas ni neolíticos en las Altas, lo que abundaría en la hipótesis de que ambas pudieron ser estancas entre sí durante sus diferentes momentos 
de utilización. Sin embargo, no puede ni debe inferirse a partir de esta simple circunstancia que las manifestaciones artísticas se correspondan cronológicamente con los períodos que sugieren sus respectivos contextos arqueológicos.

\section{- SIMA DE LA CURRA}

La prospección realizada por J.L. Sanchidrián, además de los motivos artísticos, ofreció numerosos restos cerámicos, óseos y algunos líticos. Encuadrados cronológico-culturalmente en un Calcolítico con substrato Neolítico final y relacionado con el horizonte megalítico occidental, estos vestigios parecen evidenciar un uso eminentemente sepulcral de esta cavidad (Sanchidrián 1984: 244), incluidas las muestras artísticas (Sanchidrián 1984-85: 238). La localización de algunos de estos objetos muebles, en las inmediaciones de los grupos pictóricos, merece cierta atención. Exactamente en la perpendicular del antropomorfo en " $\mathrm{H}$ " invertida fueron hallados fragmentos de un cuenco hemiesférico, "supuesta ofrenda al ídolo dibujado" (Sanchidrián 1984-85: 238). Bajo el tercer grupo, junto a otras piezas de cerámica, cuentas de collar y varias lascas y láminas de sílex, apareció un hacha de piedra pulimentada que aún conservaba restos de pigmento rojo (Sanchidrián 1984-85: 236 y 246). Por último, en las proximidades del cuarto grupo, se localizó otra importante acumulación de restos cerámicos, uno de los cuales, un vaso de cuerpo globular con decoración incisa a base de líneas, contenía aún restos de pigmento rojo (Sanchidrián 1984-85:231 y 246). Del análisis de esta substancia llevado a cabo por el Departamento de Cristalografía y Mineralogía de la Universidad de Granada mediante el método de difracción de rayos $\mathrm{X}$ se obtuvieron los porcentajes estimados en su composición: $45 \%$ de hematites, $45 \%$ de calcita y $10 \%$ de cuarzo (Sanchidrián 1984-85: 247). La costumbre de colorear en rojo objetos rituales está muy vinculada al mundo funerario megalítico (Almagro y Arribas 1963: 175), aunque no faltan exponentes trogloditas en esta misma provincia, caso de la Cueva del Tesoro en Torremolinos, Hoyo de la Mina y Cueva de Nerja (Sanchidrián 1984-85: 246). Así mismo, la estructura morfológica de esta cueva ha sido comparada con la de un sepulcro de corredor (Sanchidrián 1984-85: 245) cumpliendo una posible función sustitutoria del monumento megalítico.

\section{— RAJA DE RETUNTÚN}

Como hemos comentado, esta estación es una de las pocas localizadas en abrigo cuyos suelos permitirían la práctica de sondeos capaces de ofrecer vestigios materiales susceptibles de ser relacionados con la actividad pictórica, aunque aparecen tan revueltos que las posibles estratigrafías resultantes no serían, tal vez, del todo fiables. En efecto, una vez traspasada la primera zona de bloques desprendidos del techo a consecuencia de su derrumbamiento parcial (Muñoz 1990: 258), el piso pasa a ser de sedimentos arcillosos. En la zona izquierda hemos observado algunos restos cerámicos superficiales de escasa entidad. Al fondo de la sala, también en superficie, fueron hallados otros restos de cerámica, algunos de gran tamaño pertenecientes a un vaso neolítico de gollete. Entre el material calcolítico, formado sobre todo por restos de cuencos globulares y hemiesféricos, destaca un fondo de vasija. Así mismo, sobresale una pequeña hacha pulimentada cuyo filo presenta abundantes huellas de uso. Este material, posiblemente perteneciente a un ajuar de enterramiento, fue recogido en superficie durante las prospecciones arqueológicas realizadas en el valle del río Turón (Ramos et al. 1987 a; Espejo y Cantalejo 1989; Espejo et al. 1989), siendo depositadas en el Museo Municipal de Ardales. 


\section{- CUEVA DE LAS PALOMAS}

Su situación en el Tajo del Molino, inmediata a la estación $n^{\circ} 1$, y el calibre de la intervención de que fue objeto la convierten en referencia obligada. Las campañas arqueológicas realizadas por el Departamento de Prehistoria de la Facultad de Filosofía y Letras de la Universidad de Málaga entre los años 1975 y 1978, dieron como resultado un interesante lote de materiales cerámicos, líticos y óseos, fruto de su prospección superficial y, sobre todo, de los trabajos de excavación, realizados sobre una extensión de $6 \mathrm{~m}^{2}$ en una zona próxima a la boca que se abre al tajo. Su estratigrafía reveló la existencia de tres niveles, uno superficial, correspondiente a las últimas fases de ocupación durante el Calcolítico inicial y pleno; otro más profundo y espeso que representa una misma fase cultural de transición del Neolítico al Cobre; y un último nivel que podría suponer un substrato epipaleolítico sensu lato (Ferrer y Fernández 1986-87). Los indicios funerarios presentes en los niveles calcolíticos de la cueva, suponen otra evidencia de perdurabilidad de esta costumbre tan arraigada en el Neolítico, que se suma a otros casos malagueños como los de las cuevas de Nerja (Jordá et al. 1983: 63-64), del Tesoro (Navarrete 1976: 372-373 y 405) y de La Curra (Sanchidrián 1984-85).

También procedente de este yacimiento es un pequeño fragmento de barro cocido $(3 \times 2,7 \mathrm{~cm}) \mathrm{de}$ esquema compositivo bitriangular del que sólo se conserva la parte superior, con atributos oculares señalados mediante dos orificios y posible representación de los senos indicados con sendas protuberancias. Como hemos comentado respecto a los items de características morfológicamente similares de Las Aguilillas, los esquemas bitriangulares no sólo son propios del arte mueble, sino que también encuentran paralelos conceptualmente próximos en el arte rupestre. No obstante, el "ídolo" de la Cueva de Las Palomas mantiene afinidades atributivas mucho más cercanas que aquellos con las clásicas "venus" calcolíticas de Benaoján y Nerja.

\section{- TAJO DEL MOLINO, 3 (TE-7)}

Existe junto al abrigo del Tajo del Molino, 2 otro de mayores dimensiones que hemos clasificado como Tajo del Molino, 3. Aunque carente de representaciones artísticas, dicho abrigo contiene en superficie gran cantidad de restos cerámicos, pero su suelo, de potencia aparentemente prometedora, muestra signos de haber sido bastante removido. En una somera prospección hemos localizado un gran fragmento de cerámica a la almagra de $1,5 \mathrm{~cm}$ de espesor máximo, con fuertes concreciones; un borde también de cerámica a la almagra menos grueso que el anterior; dos bordes de cuencos hemiesféricos de paredes lisas y finas, pasta oscura de textura grosera y cuidadas superficies bruñidas; y una falange sin signos de manipulación. Son formas que pueden compararse fácilmente con las halladas en la práctica totalidad de asentamiemtos malagueños encuadrados hacia un Neolítico final-Calcolítico. Para los bordes de cuencos hemiesféricos encontramos paralelos locales muy claros, entre los que destacaremos los de la cercana Cueva de las Palomas (Aguado y Baldomero 1979: 39), la Sima de la Curra (Sanchidrián 1984-85: 233) y la Cueva de Ardales (Sanchidrián 1989: 212).

El desfiladero del Tajo del Molino y su entorno debió ser una zona de asentamiento de grupos neolíticocalcolíticos, atestiguada tanto por los materiales hallados en este abrigo como por los encontrados en la vecina Cueva de Las Palomas y en otras existentes en el mismo tajo. También las grietas tectónicas que se instalan en la base de éste debieron estar ocupadas en esa época, algunas de las cuales, incluso otras localizadas a más altura, pudieron servir como lugar de enterramiento (Recio 1991: 414). 


\section{- ÍDOLO DE ALMARGEN}

Por último, hemos creído oportuno incluir en este apartado un objeto hallado en la localidad de Almargen que, aunque no se relaciona directamente con las estaciones artísticas que estudiamos ni se conoce el contexto concreto de su hallazgo, sí atiende a lo que vendría a constituir la faceta escultórica del fenómeno esquemático. Se trata de una pieza que se ha convenido en llamar "ídolo de Almargen" (Villaseca 1993-94). Realizada en mármol, mide $48 \mathrm{~cm}$ de longitud y pesa $22,250 \mathrm{~kg}$, teniendo una forma oval y alargada y sección circular. Su extremo superior queda señalado por una representación facial enmarcada por un ribete que define los arcos orbitales y la nariz, estando representados los ojos por círculos en relieve. El otro extremo presenta una protuberancia a modo de glande. Finalmente, un abultamiento a media altura de la pieza parece mostrar al "ídolo" preñado (Villaseca 1993-94: 37-38). Se trata pues de una creación simbólica en la que se conjugan tres elementos iconográficos: la faz, el falo y el embarazo. Su adscripción cronológica parece apuntar hacia el Calcolítico en un segmento entre el 2500-1500 a.n.e. (Villaseca 1993-94: 44).

\section{MARCO CRONOLÓGICO}

De este sucinto acercamiento al registro arqueológico relacionado contextualmente con representaciones artísticas postoaleolíticas puede inferirse la acotación de ciertos márgenes que vendrían a delimitar un amplio encuadre cronológico:

- Neolítico final - Calcolítico: Cueva de Ardales. Sima de la Curra. Raja de Retuntún. Cueva de las Palomas. Tajo del Molino, 4.

- Calcolítico final - Bronce inicial: Necrópolis de las Aguilillas.

Estos encuadres nos orientan sobre los parámetros cronológicos entre los que debió desarrollarse el arte esquemático en esta zona, contándose, además, con un indicador que, aunque marginal, parece poder encuadrarse hacia las fases finales del fenómeno. Nos referimos a las representaciones de barcos del abrigo del Puerto del Viento que nos remiten, tal vez, a un período tardío en el que ya existían contactos con los colonizadores orientales (Almagro-Gorbea 87).

El abanico cronológico que hemos abierto sirve, pues, para ubicar en el tiempo, por exceso, a los "artistas" esquemáticos y a sus coetáneos. Pero para abordar la cuestión del poblamiento humano de este territorio durante dicho espectro temporal vamos a analizar por separado, en principio, las cuencas fluviales que lo componen, sólo para comprobar que entre ellas existe un notable desequilibrio documental a favor de la del Turón, que ha sido examinada de un modo más sistemático (Ramos et al. 1987 a; Espejo y Cantalejo 1989; Espejo et al. 1989; Ramos, Espejo y Cantalejo 2000), proporcionando mejores ajustes cronológicos, mientras que para la del Guadalteba se cuenta con las prospecciones de los términos municipales de Teba (Recio 1991) y Cañete la Real (Recio 1993), y la aproximación de García, Martínez y Morgado (1995), todas ellas encuadradas en el Bajo Guadalteba, quedando su cuenca alta muy poco estudiada. He aquí un inventario de los yacimientos que hemos tenido en cuenta:

\section{- CUENCA DEL TURÓN}

1) Asentamientos:

- Neolítico-Calcolítico: El Espolón. Cueva de Ardales.

- Neolítico-Calcolítico-Bronce: Peña de Ardales. El Cerrajón. 
- Calcolítico: Cortijo de S. Miguel. El Mirador. Olivar de Curro. El Vivero.

- Calcolítico-Bronce: Parque Ardales. Loma del Infierno. Morenito.

2) Necrópolis:

- Calcolítico-Bronce: Cerro de Las Aguilillas. Dolmen de los Llanos de Retamar. Morenito.

3) Talleres de sílex:

- Neolítico-Calcolítico-Bronce: Castillo de Turón. La Galeota. Cucarra. Azulejo. Alrededores de la Cueva de Ardales. Lomas del Infierno. Morenito

\section{- CUENCA DEL GUADALTEBA}

1) Asentamientos:

- Neolítico: Cueva de Las Palomas. Nina Baja. Cortijo del Tajo. Abrigo de Peñarrubia. Herriza de Priego. Esparragal. Camino la Canaleja.

- Calcolítico: Hoz de Peñarrubia. La Cuevecilla. Cerro de La Corona. Cueva de Viján.

- Bronce: Los Castillejos de Teba. El Castellón de Gobantes. Huertas de Peñarrubia.

2) Necrópolis:

- Neolítico-Calcolítico: Ortegícar. Dolmen de la Lentejuela. Dolmen de las Dos Hermanas. Tholos del Higuerón.

3) Talleres de sílex:

- Neolítico-Calcolítico: Exteriores de la Cueva de Las Palomas.

\section{ENTORNO ARQUEOLÓGICO}

La valoración de estos yacimientos y del registro arqueológico que han ofrecido nos permite intentar un acercamiento, a grandes rasgos, al proceso histórico en el que el arte esquemático pudo estar implicado. El Neolítico representaría en esta zona la base socio-cultural de los poblamientos posteriores del Calcolítico, e incluso del Bronce (Ramos et al. 1987 a: 67; Espejo et al. 1989: 32). En ese período, el hábitat estaría representado por asentamientos al aire libre como los del Puerto de las Atalayas (Ramos et al. 1992), La Isla y Depósito de Agua (Ramos et al. 1987 a; Ramos, Espejo y Cantalejo 2000), el de Nina Baja (García, Martínez y Morgado 1995: 50) y los de Herriza de Priego, Esparragal y Camino la Canaleja (Recio 1993:511); en abrigos, como los de Gaitanejo (Ramos et al. 1987 b: 169-178), Cortijo del Tajo (Recio 1991: 414; García, Martínez y Morgado 1995: 50) y Peñarrubia (García, Martínez y Morgado 1995: 50); y en Cuevas, como las de Ardales (Ramos et al. 1987 b: 143-157), El Ánfora (Ramos et al. 1987 b: 159-168) y Las Palomas (Ferrer y Marqués 1978; Baldomero 1978; Aguado y Baldomero 1979; Ferrer y Fernández 1986-87). Para todos ellos puede aceptarse un horizonte neolítico evolucionado medio-final con bases económicas agropecuarias poco intensivas, manteniendo una importante actividad depredadora. Se trataría, pues, de comunidades semisedentarias que no habrían definido aún una ordenación ocupacional del territorio. No será hasta los momentos de transición al Calcolítico que, junto a la propia evolución de los poblamientos locales, se aprecien elementos novedosos de aculturación (Ferrer y Marqués 1986: 252), probablemente relacionados con la instalación tardía (Márquez 2000 b: 95), aunque definitiva, de los grupos megalíticos. 
En estas fases iniciales calcolíticas los asentamientos se caracterizan por la diversidad morfológica de las estructuras de hábitat -cuevas naturales, fondos de cabaña, estructuras y cercados subterráneos, y pequeñas estructuras de almacenaje- y por unas ocupaciones, a menudo monofásicas y temporales, en lugares no prominentes del territorio (Márquez 2000 a: 208). A estos patrones responderían yacimientos en cueva, como los de Ardales (Espejo y Cantalejo 1987 b; Sanchidrián 1989), Las Palomas (Ferrer y Marqués 1978; Aguado y Baldomero 1979) o Viján (Recio 1993: 511), y al aire libre, como el del Cortijo de San Miguel (Fernández et al. 1995-96), con fondos de cabaña y campo de silos, en el que las actividades depredadoras del medio parecen prevalecer aún sobre las agrícolas. Con este período se identifican también los poblados de El Mirador (Ramos et al. 1986: 105), Hoz de Peñarrubia (García, Martínez y Morgado 1995: 59-64), La Cuevecilla (García, Martínez y Morgado 1995: 64) y tal vez el de El Vivero. El carácter no permanente de estos asentamientos delegaría la construcción espacial del territorio en las estructuras funerarias (Márquez 2000 a: 211). Los dólmenes de las Dos Hermanas (Recio 1993: 511), La Lentejuela (Recio 1991: 414) y, tal vez, el Tholos del Higuerón (Recio 1991: 141), en la cuenca del Guadalteba, y el desaparecido de Llanos de Retamar en la del Turón, responden a esta concepción organizativa del paisaje mediante una dispersión intencionada y estratégica (Márquez 2000 a: 212). En el marco de este ritual de enterramiento colectivo, las prácticas funerarias detectadas en cuevas, cuyos casos más significativos serían los de las cuevas de Ardales y Las Palomas o la Sima de la Curra, han sido entendidas también como una "variante kárstica del Megalitismo" (Sanchidrián 1984-85: 245-246; Márquez 2000 a: 212).

A mediados del III Mil. a.n.e. parece generalizarse un cambio significativo en las estrategias de poblamiento, con una ocupación más densa que se traduce en un incremento en el número de yacimientos. Así mismo, se documenta una intensificación de la agricultura, una clara tendencia hacia la sedentarización, articulada en función, sobre todo, de los asentamientos al aire libre, y cierta jerarquización en la distribución de los poblados (Ramos, Espejo y Cantalejo 2000). Del análisis de su cultura material se desprende un panorama representado por comunidades campesinas no metalúrgicas con sistemas socioeconómicos de ocupación descentralizada y uso extensivo e integral del territorio, sin que podamos advertir una preponderancia en la explotación de unos recursos sobre otros (Fernández 1988: 106).

Aunque se aprecie una continuidad desde el Neolítico en algunos asentamientos (El Espolón, Peña de Ardales, Cueva de Ardales, El Cerrajón), muchos lo son de nueva planta (Morenito, Vivero, Olivar de Curro, Lomas del Infierno). Sin que existan grandes poblados, parece deducirse de su distribución espacial un gran interés por el control del territorio y por la situación de los emplazamientos en lugares propicios para el mejor aprovechamiento de los recursos, como vegas y piedemontes (Espejo et al. 1989: 33). En muchos casos, como ocurre en el resto de la provincia, la elección de los enclaves está muy condicionada por la proximidad de afloramientos de sílex relacionados con espacios de taller (Ferrer y Marqués 1986: 254), dedicados fundamentalmente a la producción de herramientas agrícolas y útiles de caza. Este hecho se confirma en Lomas del Infierno y Morenito (Espejo et al. 1989: 32), asentamientos que cuentan también con espacios funerarios asociados (Espejo y Cantalejo 1989-90: 39). En el tránsito del Neolítico al Calcolítico se sitúa el taller próximo a la Cueva de las Palomas (Ferrer y Fernández 1986-87: 13-14; Márquez 1995-96: 65). Otro taller lítico relacionado con hábitat en cueva es el localizado en los alrededores de la de Ardales (Espejo y Cantalejo 1989-90: 39). También existen talleres pequeños aislados como los de Cucarra y Azulejo, aunque son, sin duda, los grandes talleres del Castillo del Turón (Ramos, Espejo y Cantalejo 1986) y de la Galeota (Espejo y Cantalejo 1989-90) los que han ofrecido mejores posibilidades de análisis. La utilización de estas fuentes de recursos se prolonga hasta el II Mil. a.n.e. (Ramos, Espejo y Cantalejo 2000. Tabla 1), lo que indica una larga perduración de las estrategias subsistenciales. 


Al final de este período comienza a documentarse un cambio decidido en los patrones de asentamiento y se buscan enclaves vinculados a puntos estratégicos. Tal es el caso de Peña de Ardales, Parque Ardales, Espolón del Guadalhorce-Kontiki (Ramos, Espejo y Cantalejo 2000) o Cerro de La Corona (García, Martínez y Morgado 1995: 70). Por otro lado, se detectan también formas de producción no locales que verifican su inclusión en redes de redistribución de objetos exóticos, como las cerámicas campaniformes localizadas en Lomas del Infierno, Carrajón y Peña de Ardales o los primeros productos metalúrgicos (Ramos, Espejo y Cantalejo 2000). La lógica de los acontecimientos va a desarticular paulatinamente el sistema poblacional basado en la "parcelación pactada del paisaje" (Márquez 2000 b: 114) y las tumbas megalíticas dejarán de ser el único referente territorial. El registro arqueológico ofrece, en cambio, nuevos modelos de inhumación como las cuevas artificiales -Necrópolis de las Aguilillas (Ramos et al. 1995; 1997; 1999)- o las cistas -La Bolina, Olivar de Jorge, Morenito, Raja del Boquerón, Lomas del Infierno (Espejo et al. 1989; Ramos, Espejo y Cantalejo 1989)-. También se observa una tendencia más decidida, que excede los límites de esta zona, hacia emplazamientos poblacionales cada vez más elevados y en cerros aislados, proceso que culminará con las estructuras eminentemente defensivas características de las sociedades más belicosas y jerarquizadas del Bronce inicial (El Castillón, El Cerrajón, Peña de Ardales) y pleno.

\section{CONCLUSIONES}

En resumen, parece confirmarse, también aquí, que las sociedades que desarrollaron estas formas esquemáticas se hallaban inmersas en el proceso de cambio, lento pero irreversible, que tuvo lugar, de forma especialmente intensa hacia el mediodía peninsular entre el $\mathrm{IV}^{\circ}$ y el $\mathrm{II}^{\circ}$ Milenio antes de nuestra era, abarcando el Neolítico, el Calcolítico y la Edad del Bronce y que estuvo protagonizado por comunidades que pasaron de la trashumancia al sedentarismo, de la depredación a la producción y de la tribalización a la jerarquización. El mundo de las creencias aparece entonces fuertemente mediatizado por el "culto a los muertos", cuyos ritos funerarios, muy vinculados al fenómeno megalítico, estuvieron también sujetos a esos cambios, pasándose de las inhumaciones colectivas a las individuales ${ }^{*}$. Colectivización e individualismo son términos que definen bien los extremos del proceso y las manifestaciones rupestres no debieron ser ajenas a este devenir. De hecho, en la medida en que se acepta que el arte esquemático venía a cumplir una función o a cubrir una necesidad social, cabe admitir que también pudo estar sujeto a los cambios que se produjeron en las sociedades que le daban sentido. $O$, dicho de otra forma, los cambios sociales debieron tener alguna incidencia o repercusión en el arte, ya fuera de carácter formal, conceptual o funcional. Lamentablemente, en el estado actual de nuestro conocimiento, dicho proceso paralelo resulta imposible de rastrear. Sin embargo, la caída en desuso de estas formas expresivas que se observa en las etapas del Bronce previas a las colonizaciones orientales, sugiere que el estilo esquemático estaba ya en franco declive cuando estas se produjeron. Desarrollando hipótesis de trabajo que justificaran este hecho en una mecánica interna, nos planteamos en principio la posibilidad de que las tendencias jerarquizantes pudieran llevar implícitas tanto la paulatina apropiación de los significados por parte de los grupos de dominio emergentes como, incluso, la introducción de formas cada vez más conceptualizadas, en una dinámica en la que el conocimiento de los códigos de significación quedaría finalmente restringido y reservado a las elites. Estas los incorporarían como valor de prestigio y/o como instrumento de coerción mediante la manipulación y/o la interpretación sesgada de

* El carácter estrictamente funerario que parece confirmarse en algunas estaciones como la Necrópolis del Cerro de las Aguililias o la Sima de la Curra, sugiere que los vestigios pictóricos hallados en ellas pudieron guardar estrecha relación con los ritos mortuorios, aunque de ninguna manera esta valoración puede hacerse extensiva al resto de estaciones, si bien muchas de ellas evidencian signos de la realización de estas prácticas. 
los contenidos, desvirtuando así su sentido originario, que sería probablemente de conocimiento y dominio público (Martínez 1998). Pero la validez de esta hipótesis radica en el grado de tipificación que se otorgue al concepto "código". A pesar de la proliferación de estereotipos, a los que, por otro lado, ni siquiera cabe atribuir con seguridad significados concretos o de conocimiento generalizado, gran parte de las formas esquemáticas resultan inclasificables. No estamos, por lo tanto, ante un lenguaje lo suficientemente codificado como para permitir su "lectura" automática y, en muchas ocasiones, ni siquiera simbólica, metafórica o metonímica (Baldellou 2001: 34), sino frente a un modo de fijar ideas por medio de formas de convención estilística antes que conceptual, articuladas arbitrariamente en combinaciones aún presintácticas, ambiguas por polivalentes, meramente evocadoras y probablemente indescifrables sin el complemento previo o simultáneo de la palabra. La impresión indeleble, tanto en la roca como en la retina, que supone la imagen, se habría incorporado, pues, al bagaje cultural como medio eficaz para rememorar, reivindicar o perpetuar la tradición oral, pero únicamente a modo de guión reminiscente, en muy contados casos interpretable por sí misma. Consecuentemente, tanto la comprensión de los contenidos como el mantenimiento y la continuidad de la información habrían dependido, más que del estricto conocimiento de unos códigos, de la capacidad de transmisión personal en el seno de la comunidad que ocupaba determinado territorio, y no serían plenamente extrapolables a otras comunidades, con las que sólo se compartiría el tópico y reiterativo manierismo técnico y estilístico. El paulatino abandono de estos usos refleja su incompatibilidad con la nueva realidad social propiciada por el desmantelamiento de la base tribal y la implantación de los primeros sistemas clasistas, cuyo eje giraba en torno al control de una minoría sobre un territorio y su producción. Así, además de afectar a comportamientos y mentalidades, los nuevos modos de redistribución de la riqueza que, finalmente, se impusieron a los colectivos-que no igualitarios-, supusieron, sobre todo, la suplantación de las formas de ocupación por las de dominio, mediante un reordenamiento territorial en el que las imágenes habrían acabado perdiendo el carácter señero que hasta entonces contribuyera -al igual que las estructuras funerarias megalíticas-a identificar el espacio ocupado y usado tradicionalmente por una comunidad, y a legitimar el reconocimiento de ese paisaje como propio (Martínez 1998; Bueno y Balbín 2000).

\section{BIBLIOGRAFÍA}

AGUADO, T. y BALDOMERO, A. (1979): "Estudio de los materiales de superficie de la Cueva de las Palomas, Teba (Málaga)", Mainake I: 29-59.

ALMAGRO-GORBEA, M. (1987): "Representaciones de barcos en el arte rupestre de la Península Ibérica. Aportación a la navegación pericolonial desde el Méditerráneo Oriental", Actas del Congreso Nacional "El Estrecho de Gibraltar», I: 389-398. Madrid.

ALMAGRO BASCH, M. (1966): Las Estelas decoradas del Suroeste Peninsular, Bibliotheca Praehistorica Hispana III. Madrid.

ALMAGRO, M. y ARRIBAS, A. (1963): El poblado y la necrópolis megalíticos de Los Millares (Santa Fe de Mondújar, Almería), Bibliotheca Praehistorica Hispana III. Madrid.

ALMAGRO GORBEA, M ${ }^{\mathrm{a}}$.J. (1973): Los ídolos del Bronce I Hispano, Bibliotheca Praehistorica Hispana XII. Madrid.

BALDELLOU, V. (2001): "Semiología y Semiótica en la interpretación del arte rupestre postpaleolítico", Semiótica del Arte Prehistórico. Servicio de Estudios Arqueológicos Valencianos. Serie Arqueológica 18:25-51. Diputación Provincial de Valencia. Valencia.

BALDOMERO NAVARRO, A. (1978): "Noticia del hallazgo de un vaso del eneolítico", Baetica 1: 167-168.

BARROSO, C. y MEDINA, F. (1989): "El conjunto rupestre de arte postpaleolítico de Peñas de Cabrera. Casabermeja, Málaga”, Anuario Arqueológico de Andalucía. II Actividades Sistemáticas: 333-345. Sevilla. 
BÉCARES PÉREZ, J. (1990): “Uniformidad conceptual en los ídolos del Calcolítico peninsular”, Zephyrvs XLIII: 88-93.

BUENO, P. y BALBÍN. R. (2000): “Art mégalithique et art en plein air: Approches de la définition du territoire pour les groupes producteurs de la péninsule ibérique", L'Anthropologie 104: 427-458.

CANTALEJO, P. y ESPEJO, M.M. (1988): “Cueva de Ardales, yacimiento recuperado", Revista de Arqueología 84: 14-24.

(1995): “Arte rupestre de la Cueva de Ardales", Geología y Arqueología Prehistórica de Ardales: 95-110. Ardales.

CANTALEJO, P.; ESPEJO, Ma.M. y RAMOS, J. (1997): Cueva de Ardales. Guía del legado histórico y social. Ayuntamiento de Ardales. Ardales.

DAMS, L. y DAMS, M. (1983): "Iconographie complémentaire de la grotte de Doña Trinidad à Ardales (Málaga)", Bulletin de la Sociètè Royale Belge d'Anthropologie et de Préhistoire 94: 107-125.

(1984): Ships and boats in the prehistoric rock-art of Southern Spain, en T.F.C. Blagg et alii (Ed.). Papers in Iberian Archaeology. BAR Int. Ser. 193: 1-12.

DURÁN, J.J. (1987): “Cueva de Ardales. Geología”, en Cueva de Ardales, su recuperación y estudio: 47-56. Ayuntamiento de Ardales. Ardales.

ESPEJO Ma.M. y CANTALEJO, P. (1987 a): “Cueva de Ardales. Arte rupestre paleolítico", en Cueva de Ardales, su recuperación y estudio: 67-116. Ayuntamiento de Ardales. Ardales.

- (1987 b): "Cueva de Ardales. Las Galerías Altas", en Cueva de Ardales, su recuperación y estudio: 117-126. Ayuntamiento de Ardales. Ardales.

- (1989): "Informe Sobre las prospecciones arqueológicas superficiales realizadas en el valle del Turón. Málaga, 1988", Anuario Arqueológico de Andalucía. II Actividades Sistemáticas: 108-115. Sevilla.

- (1989-90): “La Galeota, un taller de sílex calcolítico (Ardales, Málaga)”, Mainake XI-XII: 21-40.

ESPEJO, Mª.M.; RAMOS, J.; CANTALEJO, P. y MARTÍN, E. (1989): “Análisis espacial e histórico en el valle del río Turón", Revista de Arqueología 93: 30-37.

ESPEJO, Ma .M.; RAMOS, J.; RECIO, A.; CANTALEJO, P.; MARTÍN, E.; CASTAÑEDA, V. y PÉREZ, M. (1994): "Cerro de las Aguilillas. Necrópolis colectiva de cuevas artificiales", Revista de Arqueología 161: 15-23.

FERNÁNDEZ RUIZ, J. (1988): "Factores que intervienen en la situación de los asentamientos durante las primeras etapas metalúrgicas en la provincia de Málaga", Baetica 11: 195-211.

FERNÁNDEZ, L.E.; NAVARRO, I.; SUÁREZ, J.; SOTO, A.; SANTAMARÍA, J.A.; ARANCIBIA, A.Ma . y RODRÍGUEZ, F.J. (1995-96): "La excavación arqueológica de urgencia del yacimiento calcolítico del Cortijo de San Miguel. Ardales, Málaga. C-341, Ardales-Campillos”, Mainake XVII-XVIII: 43-54.

FERRER, J.E. y MARQUÉS, I. (1978): "Avance a las campañas arqueológicas realizadas en la Cueva de las Palomas. Teba (Málaga)", Baetica 1: 195-206.

- (1986): "El Cobre y el Bronce en tierras malagueñas", en Homenaje a Luis Siret (Cuevas de Almanzora, 1984): 251-261.Sevilla.

FERRER, J.E. y FERNÁNDEZ, J. (1986-87): “Avance al estudio de la industria en sílex de la Cueva de las Palomas (Teba, Málaga)", Mainake VIII-IX: 5-23.

GARCÍA SERRANO, R. (1979-80): "Necrópolis en cuevas artificiales en Archidona (Málaga)", Ampurias 41-42: 371-375.

GARCÍA E.; MARTÍNEZ, V. y MORGADO, A. (1995): El bajo Guadalteba (Málaga): Espacio y poblamiento. Una aproximación arqueológica a Tebay su entorno. Excmo. Ayto. de Teba. Diputación Provincial de Málaga. Málaga.

GIMÉNEZ REYNA, S. (1963): La Cueva de Doña Trinidad en Ardales. Publicaciones de la Caja de Ahorros Provincial de Málaga. Málaga. 
JORDÁ, F.; JORDÁ, J.; GONZÁLEZ-TABLAS, F.; AURA, J.E. y SANCHIDRIÁN, J.L. (1983): "La Cueva de Nerja", Revista de Arqueología 29: 56-65.

LEIVA, J.A. y RUIZ GONZÁLEZ, B. (1977): “Materiales arqueológicos de la Cueva de Belda”, Jábega 19: 3-9.

MARQUÉS MERELO, I. (1987): “El yacimiento de Alcaide(Antequera, Málaga). Campaña de excavaciones de 1987”, Anuario Arqueológico de Andalucía. II Actividades Sistemáticas: 268-270. Sevilla.

MARQUÉS, I. y FERRER, J.E. (1979): "Las campañas de excavaciones arqueológicas en la necrópolis de Alcaide, 1976", Mainake I: 61-84.

(1983): “Aportaciones al primer horizonte cronológico de la necrópolis de Alcaide (Antequera, Málaga)", XVI Congreso Nacional de Arqueología: 227-238. Zaragoza.

MÁRQUEZ ROMERO, J.E. (1995-96): "La producción lítica tallada de las comunidades de la Edad del Cobre y del Bronce en la provincia de Málaga", Mainake XVII-XVIII: 55-72.

- (2000 a): "Territorio y cambio durante el III milenio a.C.: propuestas para pensar el tránsito del Calcolítico a la Edad del Bronce", Baetica 22: 203-230.

(2000 b): El Megalitismo en la provincia de Málaga. Breve guía para su conocimiento e interpretación, Conocer Málaga, 6. Universidad de Málaga.

MARTÍNEZ GARCÍA, J. (1998): "Abrigos y accidentes geográficos como categorías de análisis en el paisaje de la pintura rupestre esquemática. El sudeste como marco", Arqueología Espacial, Arqueología del Paisaje 19-20: 543-561.

MAURA MIJARES, R. (2001) “El Abrigo de la Casilla del Búho (Cañete la Real): otro hito del esquematismo prehistórico malagueño", Mainake XXI-XXII: 255-258.

(2003): "Las pinturas rupestres esquemáticas de la Raja de Retuntún (Casarabonela, Málaga): fundamentos para su revisión”, Zephyrvs LV: 331-336.

MORALES, A. y MÁRQUEZ, J.E. (1984): "Las pinturas esquemáticas malagueñas y sus relaciones con culturas materiales", Arqueología Espacial 3: 175-195.

MUÑOZ VIVAS, V.E. (1990): “Raja de Retuntún: una nueva estación con representaciones esquemáticas", Zephyrvs XLI-XLII: 257-262.

NAVARRETE ENCISO, Ma ${ }^{\mathrm{a}}$.S. (1976): La Cultura de las Cuevas con cerámica decorada en Andalucía Oriental. Granada.

RAMOS, J.;ESPEJO, Mª.M. y CANTALEJO, P. (1986): Taller calcolítico del Castillo de Turón. Ardales, Málaga. Ayuntamiento de la Villa de Ardales. Ardales.

_- (1989): “Arte rupestre esquemático en el Alto Vélez: el abrigo de Marchamonas", Revista de Arqueología 99:12-16.

- (2000): "La formación social clasista inicial en los entornos de Ardales (milenios III y y I' a.n.e.)", III Simposio de Prehistoria Cueva de Nerja. "Las primeras sociedades metalúrgicas en Andalucia". Nerja (en prensa).

RAMOS, J.; ESPEJO, M ${ }^{\mathrm{a}}$.M.; CANTALEJOP. y MARTÍN, E. (1987 a): "Informe sobre las prospecciones arqueológicas superficiales realizadas en el valle del Turón, término municipal de Ardales (Málaga)", Anuario Arqueológico de Andalucía. II Actividades Sistemáticas: 66-72. Sevilla.

(1987 b): "El Neolítico en la Cueva de Ardales", en Cueva de Ardales, su recuperación y estudio: 141-230. Ayuntamiento de Ardales, Ardales. 
RAMOS, J.; ESPEJO, Mª.M.; CANTALEJOP.; MARTÍN, E. y RECIO, A. (1992): "Puerto de las Atalayas (Ardales, Málaga). Una aldea eneolítica al aire libre", Butlletí de L'Associació Arqueológica de Castelló 12: $27-44$.

(1995): "Las ocupaciones prehistóricas de la Cueva de Ardales (Ardales, Málaga)", en Geología y Arqueología Prehistórica de Ardales: 111-123. Ardales.

RAMOS, J.; ESPEJO, Ma.M.; RECIO, A.; CANTALEJO, P.; MARTÍN, E.; PÉREZ, M.; CASTAÑEDA, V.; DURÁN, J.J. y CÁCERES, I. (1997): "La necrópolis colectiva del Cerro de las Aguilillas (ArdalesCampillos, Málaga). Inferencias socioeconómicas”, Revista Atlántica-Mediterránea de Prehistoria y Arqueología Social 1: 159-180.

- (1999): "Excavación arqueológica de urgencia en la necrópolis colectiva de cuevas artificiales del cerro de las Aguilillas (Ardales-Campillos, Málaga). Informe preliminar", Anuario Arqueológico de Andalucía. III Actividades de Urgencia: 355-361. Sevilla.

RAMOS, J.; ESPEJO, Ma.M.; CANTALEJO, P.; DURÁN, J.J.; MARTÍN, E. y RECIO, A. (1997-98): "Cueva de Ardales (Málaga): Geocronología Evolutiva y cambios climáticos en el Pleistoceno Superior y Holoceno. Los testimonios de su ocupación por formaciones sociales de cazadores-recolectores, tribales y clasistas iniciales", Mainake XIX-XX: 17-45.

RECIO RUIZ, A. (1991) "Informe arqueológico del término municipal de Teba (Málaga)", Anuario Arqueológico de Andalucía. III Actividades de Urgencia: 413-418. Sevilla.

(1993): "Prospecciones arqueológicas en Cañete la Real (Málaga)", Anuario Arqueológico de Andalucía. III Actividades de Urgencia: 509-512. Sevilla.

RIVERO GALÁN, E. (1986): "Ensayo tipológico de los enterramientos colectivos denominados cuevas artificiales en la mitad meridional de la Península Ibérica", Habis 17: 371-401.

RUIZ, B. y LEIVA, A. (1980-81): "Ídolo oculado de la Cueva de Belda (Cuevas de San Marcos, Málaga)" Mainake II: 76-86.

SANCHIDRIÁN TORTI, J.L. (1982): "Ídolos femeninos esquemáticos de la Cueva de Nerja", Zephyrvs XXXIV-XXXV: 103-107.

(1984-85): "Algunas bases para el estudio de los actos funerarios eneolíticos: Sima de la Curra (Carratraca, Málaga)”, Zephyrvs XXVII-XXXVIII: 227-248.

(1987): “Aportaciones al acervo artístico esquemático de la provincia de Málaga”, XVIII Congreso Nacional de Arqueología: 497-511. Islas Canarias.

SANCHIDRIÁN, J.L.; MUÑOZ VIVAS, V.E. y FERNÁNDEZ, L.E. (1989): "La presencia eneólitica en las galerías altas de la Cueva de Doña Trinidad (Málaga)", X1X Congreso Nacional de Arqueología. Tomo I: 209-226. Zaragoza.

VILLASECA DÍAZ, F. (1993-94): “Aportación al estudio de la iconografía prehistórica: los ídolos de Almargen y Antequera”, Mainake XV-XVI: 37-44. 